\title{
Breve ensayo sobre La República de Platón y los universales de Russell: acerca del carácter práctico del idealismo de Platón y el carácter contemplativo del materialismo de Russell a la luz de Marx
}

BEATRIZ ESCOBAR

Departamento de Economía Universidad Centroamericana "José Simeón Cañas"

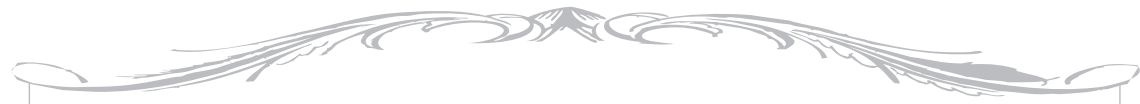

\section{Resumen}

Este breve escrito trata sobre el conocido debate entre idealismo y materialismo, haciendo uso, para ello, del idealismo platónico presentado en La República, de cara al materialismo proclamado por Russell - proponente de los conceptos universales - como un intento de evidenciar el carácter complejo, i.e. no-completamente-dicotómico, de esta discusión. Tal cosa se realiza, además, a la luz de la concepción materialista de la historia de Marx (y Engels), postura que se adopta en tanto pensamiento transformador que implica y supone la acción, y de la que se habla de forma amplia.

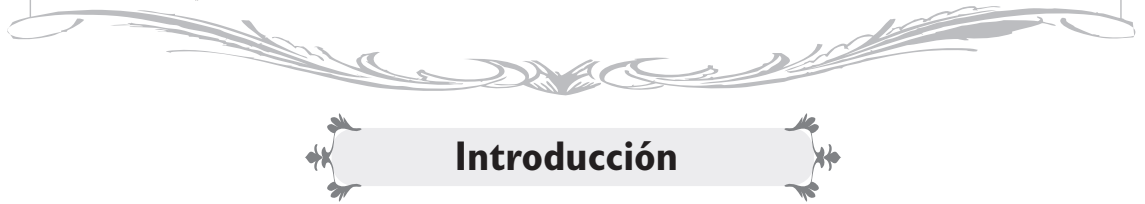

En la página 231 de La República de Platón (Macdonald, 1955), encontramos una frase que, en nuestra opinión, resume una de las ideas fundamentales de esta obra: "De la contemplación de las cosas divinas a las miserias de la vida humana". Este es, según Platón, el viaje que "el filósofo" debe emprender con el fin de liberar e imponer el orden en la república. Sin embargo, este no es más que el camino de vuelta de un viaje anterior, viaje que podríamos denominar: "De las miserias de la vida humana a la contemplación de las cosas divinas", y que es, además, el tema que nos ocupa. 
Aunque en el contexto de La República de Platón esta frase puede referirse al entrenamiento que el filósofo debe recibir para alcanzar la contemplación del "Bien absoluto", aquí queremos implicar algo distinto, a saber: la supremacía de las condiciones materiales en la vida de las personas sobre las ideas en cada período histórico. Alegaremos que son las primeras la base de las segundas, y no lo contrario, como el pensamiento idealista sugiere; en otras palabras, que tales condiciones materiales, y las relaciones que las personas establecen sobre ellas para posibilitar sus vidas, son, ciertamente, el "mundo real".

Nuestras reflexiones no solo se circunscriben a la tradición filosófica materialista, sino que además sostienen la hipótesis de que es la existencia de seres humanos concretos $-\mathrm{y}$, por lo tanto, de las condiciones materiales necesarias para hacer posible su existencialo que genera, determina y dota de significado a la ideología de cada época, entendida como el conjunto de ideas dominantes. Es bajo esta perspectiva que queremos aproximarnos también a los universales propuestos por Bertrand Russell (1954) quien, de forma interesante, se autodenomina materialista. Tal aproximación, considerada frente al idealismo platónico, nos permitirá percibir el carácter no-completamente-dicotómico de esta discusión. Nuestra intención es retomar el imprescindible debate entre la concepción idealista y la materialista, pero a la luz de las ideas de Marx. La nuestra no es una tarea sencilla, y este no pretende ser más que un pequeño comentario. Sin embargo, haremos un esfuerzo por elegir cuidadosamente nuestros argumentos, tratando de presentarlos de forma clara y coherente con el fin de construir una sinopsis que invite, precisamente, a la discusión.

Nos ocuparemos, en la siguiente sección, de comentar la parábola platónica de la cueva, referida a las miserias de la vida humana; para pasar, a continuación, a la reflexión en torno a la forma en que Platón sugiere que es posible escapar de esta "realidad aparente": la línea, es decir, el entrenamiento del filósofo. Esta parte contiene, además, nuestras ideas en torno a los conceptos universales de Russell. La última sección encierra una discusión sobre lo que se presenta como la actitud contemplativa y sensorial del "materialista" Russell frente a la actitud transformadora y activa del "idealista" Platón. Es aquí donde los aportes de Marx entran en escena.

\section{Las miserias humanas: la cueva}

La República está marcada con una visión pesimista de la sociedad.
La situación general y, principalmente, la forma en que la política 
era llevada a cabo, así como la ejecución de Sócrates, su maestro, condujeron a Platón a observar una vasta decadencia a su alrededor, una decadencia que, además, era ignorada por la población que, según este autor, vivía lejos de la verdad y de la realidad. Es esto lo que aparece ilustrado en su alegoría de la cueva, donde, usando metáforas que el común de la gente pudiera comprender, Platón presenta la ceguera, la opresión, la bajeza y la falsedad en la cual los humanos estaban sumergidos: las miserias humanas.

En general, la observación y experimentación de tales miserias, unidas a la desesperación provocada por ellas, han llevado a las personas, históricamente, a imaginar "otros lugares", otra sociedad que no es "esta" sociedad, que más bien es su contrario, una sociedad considerada como digna de perseguir y de conservar. La forma de alcanzar la sociedad ideal de Platón es lo que La República presenta. Para Platón, la (única) manera de alcanzar dicha sociedad es nombrando monarca al filósofo, esto es, a través de un "salvador" o "libertador", previamente elegido, educado y entrenado para salir de la cueva, contemplar el mundo real (el reino de los formas eternas e inmutables, dominado por el Bien supremo), y regresar a la sociedad, sumergida en el engaño y la decadencia, para limpiarla y guiarla hacia el camino del "deber ser".
Esta sociedad ideal, sin embargo, al igual que cualquier otra sociedad, no puede ser alcanzada a menos que las condiciones materiales para su existencia estén presentes. Por ejemplo, el proceso de preparación del filósofo requiere de un sistema de educación específico (¿Quién educará al filósofo? ¿Quién educará al educador del filósofo?), lo que implica la presencia previa de condiciones materiales particulares. La existencia y el desarrollo de la ciencia y de la filosofía requieren (y han requerido históricamente) de tales condiciones. Más aún, la existencia continua del filósofo, como ser viviente, demanda de dichas condiciones: él tiene que alimentarse, que estar saludable, protegido, etc., de lo contrario no puede haber ni filósofo ni república.

Lo que es sumamente interesante en Platón es que, a pesar de no considerar estas condiciones materiales, su actitud está muy lejos de ser meramente contemplativa, es más bien una actitud activa. Su propuesta incluye no solo un intento de explicar la situación dominante, sino, además, un intento por transformarla. El peligro histórico de las utopías reside justamente en ello, en que guían la acción transformadora, en que desafían lo existente, el régimen dominante $y$, en última instancia, la forma de organización para la producción social de la vida. Es esto lo que hizo (y hace) peligroso a Platón, en el mismo sentido en que lo fuera Sócrates, condenado a muerte por ello. 


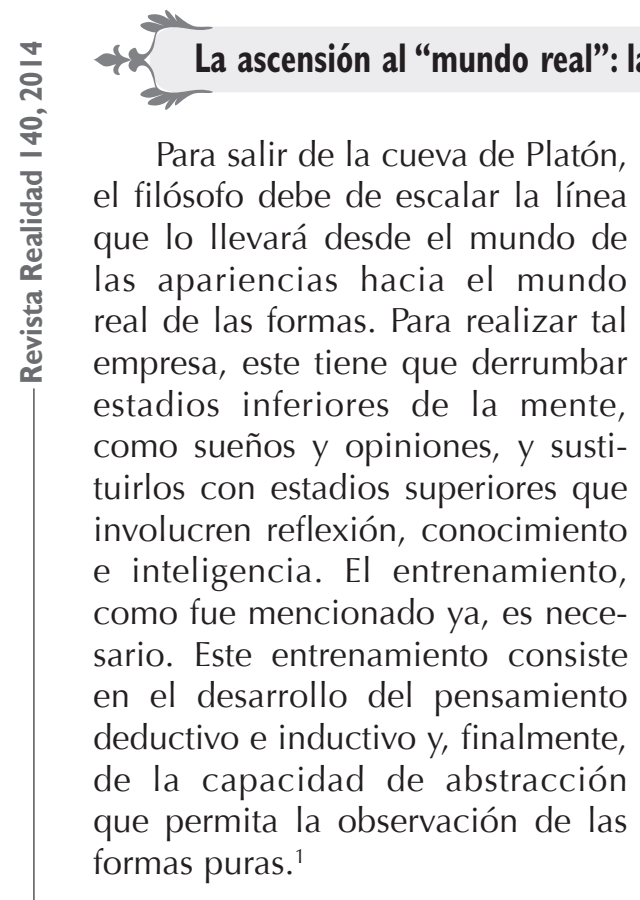

Bertrand Russell, en su obra Los problemas de la filosofía (publicada en 1912), donde presenta una defensa del materialismo sobre el idealismo, señala que aunque los desarrollos metafísicos de Platón son incorrectos, la lógica de su teoría es altamente valiosa. Russell afirma que la capacidad de reconocer una característica compartida por muchas cosas particulares, característica que no puede existir dentro del mundo sensible y que, por ende, no puede ser aprehendida a través de los sentidos, es lo que llevó a Platón a declarar que el mundo real es el reino de las ideas, en el que la esencia pura de las cosas, su idea o forma, es eterna, inmutable e indestructible. Pero es precisamente la abstracción platónica lo que Russell retoma con el fin de construir la definición de "universal".

Un universal, en oposición a un particular, es "cualquier cosa que pueda ser compartida por muchos particulares, y que tiene esas características que... distingue a la justicia y a la blancura de los actos justos y las cosas blancas" (Russell 1954, p. 93. La traducción es nuestra). Los universales de Russell, al igual que las ideas de Platón, son eternos, inmutables e indestructibles.

Para clarificar su argumento, Russell nos proporciona ejemplos utilizando conceptos geométricos y espaciales, tales como triángulos y locaciones como "al norte de". Afirma que, en el primer caso, es la relación de semejanza que cualquier triángulo comparte con otro lo que debe ser un verdadero universal; mientras que la parte de la superficie de la tierra que está al norte de cualquier otra continuará existiendo "incluso si no hubiesen seres humanos que conocen acerca de norte y sur, e incluso si no hubiese ninguna mente en todo el universo... Por lo tanto, tenemos que admitir que la relación, así como el término que esta relaciona, no depende del pensamiento, sino que pertenece al mundo independiente que el pensamiento aprehende pero no crea" (Russell 1954, p. 98. La traducción es nuestra). 
Coincidimos con los argumentos de Russell, pero no completamente. Nuestra percepción es que la existencia de universales, como categorías teóricas de una realidad determinada, sí presupone la existencia de seres humanos; que es precisamente esta existencia, y no la existencia del universal per se, lo que da sentido a la presencia empírica de estos universales; y nuestras mentes, forjadas a partir de ciertas condiciones materiales específicas, lo que hace posible su existencia como categorías teóricas, esto es, como abstracciones. El sentido de la relación "al norte de" depende de la existencia de humanos porque no es la relación "al norte de" lo que subsiste sin ellos, sino únicamente la ubicación espacial. "Al norte de" existe solo si los humanos existen, y significa algo solo si ellos le dan sentido a través de su actividad productiva y creadora. Si los universales están referidos a los humanos, como por ejemplo, la categoría "trabajo", observamos que su realidad empírica —mas no la teórica-, aparece bajo diferentes formas en todas las sociedades humanas, y que la actividad que implica dejaría de existir en el momento en que aquellos dejaran de existir. "Distancia", por otro lado, al igual que "espacio", y especialmente "materia" y "movimiento", son, en efecto, independientes de la existencia humana, pero carecen de significado y de realidad teórica sin ella. Así, los conceptos matemáticos y geométricos, por ejemplo, son conceptos humanos. Es cierto que el número 2 es eterno e inmutable, pero el concepto, la categoría en sí, existe solo mientras los seres humanos existan, y significa lo que significa únicamente gracias a ellos; más aún, fue descubierto al interior de una sociedad determinada, bajo condiciones materiales específicas.

Obsérvese que lo "material" es también una abstracción en tanto no existe lo material en general, sino materias concretas, determinadas, con cualidades particulares. Se trata, luego, de una categoría teórica, de una determinada manera de aproximarse a la realidad, lo que constituiría, prima facie, una contradicción. Pero es necesario advertir que como tal categoría, al igual que cualquier otra, esta adquiere sentido y presencia, tanto teórica como empírica, gracias a la vida y actividad humana. Lo fundamental o primigenio sigue siendo la organización socio-productiva que hace posible la existencia continua de la vida, y que responde a esa evolución de las condiciones materiales en la que la misma actividad humana está profundamente involucrada, afectando y siendo afectada por ella. $Y$ es en este sentido, y solo en este sentido, en que debe interpretarse la afirmación marxista de que es "lo económico lo determinante en última instancia". Las ideas y los conceptos abstractos no son, ciertamente, meras ilusiones, pero tampoco son 
más que sistematizaciones Ilevadas a cabo por el cerebro humano con el fin de apropiarse de la realidad que le rodea en un determinado momento histórico y en unas determinadas condiciones materiales.

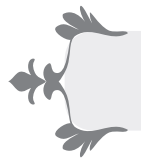

Epílogo: La actividad de los seres humanos y el materialismo histórico transformador
El filósofo de Platón es el guardián principal de la república, el que mantiene el orden y la defiende. Sin embargo, para poder defender algo, es necesario tener algo que defender, esto es, la real existencia de la república. Tal organización implica actividad, la producción y reproducción concreta de las condiciones para la vida, y no la idea de ser humano en abstracto.

Como mencionamos con anterioridad, los seres humanos, vivientes y concretos, como sujetos que dependen de ciertas condiciones materiales sobre las que establecen relaciones sociales específicas, son los que determinan, ordenan y dan sentido a las ideas y conceptos universales. No puede haber "libertad", ni "ubicación espacial" o "movimiento", como categorías teóricas con significado, como universales, sin vida humana. Incluso nuestras ideas de cómo la sociedad "debe ser" son producto de la organización social en la que vivimos y nos desenvolvemos. De modo que las ideas encaminadas a crear nuevas sociedades, nuevas condiciones y nuevas relaciones sociales de producción, así como una nueva conciencia e ideología, no pueden convertirse en reales por simple buena disposición, ni por meramente "tomar conciencia" o "cambiar de mentalidad", por "quitarse de la cabeza" ideas (normas, valores morales, etc.) propias de un modo de producción determinado y adoptar otras, sin que se modifique nada más. Son las condiciones materiales las que dan lugar a esas ideas revolucionarias, al ser, ellas mismas, producto de procesos concretos y específicos de socialización que dependen de una concreta y especifica organización social de la producción, de la observación y experimentación de sus contradicciones, ante las cuales se adopta una posición crítica y desobediente. Y su realización, su "cristalización", es, de hecho, el derribamiento práctico de la forma dominante de producir la vida. La disolución de lo existente, de "esta" sociedad, la supresión de sus relaciones sociales de producción que, habiendo agotado su "misión histórica", i.e., habiendo alcanzado su límite, deben ser reemplazadas por nuevas y superiores, implica la resolución del conflicto entre tales relaciones y las condiciones materiales existentes, en cuyo desarrollo las primeras, en lugar de contribuir, obstaculizan. Es esta la manera en 
que, de acuerdo a los fundadores del socialismo científico, se han sucedido los distintos modos de producción en la historia. ${ }^{2}$

Por lo observado hasta ahora, se sabe que la superación de relaciones sociales pertenecientes a una organización productiva determinada no garantiza, forzosa y automáticamente, la superación de la explotación, como ha sido demostrado por el paso del esclavismo al feudalismo, y de este al capitalismo. La sociedad sin clases, i.e. sin explotación, es también el resultado de un proceso de evolución histórico-social —donde el capitalismo no es más que una fase necesaria-, un pasar de estadios inferiores a estadios superiores hasta el punto en que desaparezca toda justificación y legitimidad histórica para la escisión de la sociedad en clases. Pero, para ello, no basta con que la organización socioproductiva se convierta en un poder insoportable "contra el que hay que sublevarse" (Marx y Engels 1973, p. 36) — dada la enorme masa de personas desposeídas, subyugadas y excluidas que estas relaciones han creado como producto propio-; es decir, no basta con que estén presentes, con que hayan sido producidas, las ideas revolucionarias, sino que además, y como condición absolutamente necesaria, que las fuerzas productivas experimenten un considerable desarrollo universal, ${ }^{3}$ tal que no existan bases materiales para que la explotación continúe. De no darse esta condición, el resultado de cualquier intento reivindicativo $\mathrm{y} / \mathrm{o}$ transformador no iría más allá de ser un mero compartir la escasez, i.e. repartir la pobreza, "y, por tanto, con la pobreza, comenzaría de nuevo, a la par, la lucha por lo indispensable y se recaería necesariamente en toda la inmundicia anterior" (Marx y Engels 1973, p. 36. Itálicas de los autores). De ahí las palabras de Engels en el AntiDühring (1877-1878, citado por Gill 2002, p. 36):

Pero si la división en clases tiene cierto derecho histórico de ser, lo tiene solamente para un lapso de tiempo dado, para determinadas condiciones sociales. Esta división se basa en la escasez de la producción y será barrida cuando las modernas fuerzas productivas se desplieguen en su plenitud.

Gill (2002, p. 36) hace además, a este respecto, una observación imprescindible:

En este sentido es en el que Marx habla del final de la 'prehistoria de la sociedad humana', que de ninguna 
manera debe ser interpretado como el fin de la evolución social, el fin del cambio, el fin del movimiento, el alcance de la sociedad perfecta o el paraíso en la tierra, la realización de un mundo carente de contradicciones. Los detractores de Marx han querido encontrar en tal interpretación una profunda contradicción de su método dialéctico, que se negaría a sí mismo por la conclusión a la que él conduciría, la de un sistema ideal que dejaría de evolucionar. Sin embargo, tal conclusión es completamente extraña al método marxista.

Marx y Engels estaban honestamente convencidos de que con el enorme progreso de las fuerzas productivas llevado a cabo por el capitalismo — si bien como simple medio para la obtención de ganancias-, se abría, por primera vez en la historia, la posibilidad material para la existencia de esa sociedad sin clases. Es por eso que el capitalismo era para ellos la última forma de producción que subyuga al ser humano, que le impide su realización y el despliegue de todo su potencial creativo. ${ }^{4}$ Pero tal cosa no significa, de manera alguna, ni determinismo mecánico, i.e. obligación histórica, ni mucho menos el "fin de la historia". ${ }^{5}$

Por otro lado, en ningún momento se niega, como es intencionadamente o no- ampliamente mal entendido, la participación humana en este proceso. $Y$ es que la segunda condición absolutamente imprescindible para la transformación es la existencia de un movimiento social universalmente organizado que se levante, no contra una particularidad aislada de este modo de producción (e.g., contra el gobierno o contra el neoliberalismo), sino contra la forma misma de (re)producción de la vida, contra la organización económica sobre la que esta descansa, y tal cosa se vuelve posible cuando la organización social para la producción de la vida, toda, sea verdaderamente insoportable. ${ }^{6}$

Es justamente por eso que es interesante notar - dejando de lado toda discusión acerca de las interpretaciones más bien fascistas que sería posible derivar de la obra de Platón, además del cúmulo de observaciones y críticas que podrían surgir en torno a su idea de la necesidad de un "salvador" que el idealismo platónico está colmado de una actitud activa y transformadora ante la sociedad que le rodea; mientras que el materialismo de Russell, con su idea de la información captada a través de los sentidos, así como la forma en que expone sus argumentos, convierte al ser humano en un objeto, divorciándolo de su actividad. Su concepción acerca del mundo no es más que 
una percepción sensorial, una observación pasiva, producto de un materialismo contemplativo.

El materialismo, sobre todo el histórico, no consiste en deliberar acerca de la existencia de una mesa y saber que la mesa existe porque nuestros sentidos son capaces de percibirla, de capturar su dureza, sus dimensiones, su consistencia, etc., sino en la comprensión de las condiciones que permitieron la existencia de dicha mesa, las condiciones bajo las cuales fue producida, i.e. las relaciones de producción subyacentes. Citando a Marx y Engels:

Hasta los objetos de la 'certeza sensorial' más simple le vienen dados solamente por el desarrollo social, la industria y el intercambio comercial. Así es sabido que el cerezo, como casi todos los árboles frutales, fue trasplantado a nuestra zona hace pocos siglos por obra del comercio y, tan solo por medio de esta acción de una determinada sociedad y de una determinada época, fue entregado a la 'certeza sensorial' de Feuerbach (Marx y Engels 1973, p. 47. Énfasis de los autores).

Mutato nomine, de te fabula narratur. Russell, con sus universales, se posiciona frente al mundo como un simple espectador, un intérprete, un mero teórico, pero no como un sujeto transformador, lo que de hecho, y de forma interesante, es la actitud de Platón y lo que podríamos Ilamar su "idealismo transformador". No era suficiente para él observar y vivir las miserias humanas, o incluso criticarlas; él, además, propuso una forma de transformarlas, a pesar de que tal propuesta estuviera cabeza abajo.

Si bien las ideas son, en última instancia, un resultado y no una causa, un reflejo y no un dato, $y$ como tales se encuentran social e históricamente determinadas, el materialismo burdo, estático y conformista es igualmente inútil. Ciertamente, en palabras de Marx:

Los filósofos no han hecho más que interpretar de diversos modos el mundo, pero de lo que se trata es de transformarlo (Marx y Engels 1973, sin número de página. Énfasis de los autores).

De ahí que la concepción materialista de la historia no se limite a la simple interpretación de la realidad, sino que conlleve una actitud activa, de transformación radical. Esta concepción concibe a la historia no ya como una sucesión de ideas (políticas, religiosas, 
morales, etc.) que determinan, de forma unidireccional, los eventos y la organización social de cada período histórico. Tampoco la concibe como una serie de hechos aislados, estáticos y fortuitos, como caídos del cielo, que se explican gracias a elementos situados fuera de la actividad, del modo de vida de las personas, e incluso fuera del planeta. Todo lo contrario. Se trata de la comprensión de la evolución histórica a partir de la acción de los sujetos que, a la vez, se ven retroalimentados, determinados, por ella. De las relaciones que las personas establecen para llevar a cabo la actividad productiva, i.e. para reproducir sus vidas, surge la ideología de cada época, que responde a las necesidades de funcionamiento $y$ desarrollo del modo de organización productivo vigente.

La apropiación mental de tal realidad, su teorización, el método con el que nos aproximamos a ella, debe contener la develación de tal evolución, de la complejidad y las contradicciones presentes en la realidad, la identificación de los elementos claves que nos permitan, de forma paralela, reconstruirla como un conjunto de categorías teóricas relacionadas entre sí y con el todo al que pertenecen, del cual derivan su sentido y al cual proveen de sentido; y no presentarse como una simple lista de conceptos independientes, ajenos a la actividad humana, uno al lado de otro, comprendidos de forma mecánica, estática e independiente. Tal construcción teórica requiere además del auxilio del pensamiento abstracto con el fin de percibir la realidad esencial que subyace a los fenómenos aparentes, de captar las distintas categorías y sus interrelaciones, para así comprender el funcionamiento de la organización en la que están presentes. Esta construcción teórica activa es la que permite, a su vez, una comprensión que estimula la participación en la realidad como sujetos críticos y transformadores, la desalienación de lo que parecen ser poderes extraños e indomables.

En esto consiste el materialismo dialéctico de Marx —compuesto por un modo dialéctico de pensar y una concepción materialista del mundo-, como método que explica, de forma dialéctica e histórica, la dialéctica e histórica realidad. Dicho materialismo dialéctico necesita aún de mucho desarrollo para poder hacer frente a un pensamiento idealista que, junto a un método metafísico, separa al individuo de la sociedad para estudiarlo de forma aislada como objeto dado. Es este el pensamiento que por tantos siglos se ha erigido como el dominante y que en la actualidad nos somete, en correspondencia con el modo de producción que le da soporte, al pensamiento económico burgués, así como a su método carente por completo de un análisis histórico, y que, por ende, proclama como 
eternas y naturales, formas sociales que son simplemente transitorias.?

Pero el pensamiento estáticoformal, incapaz de percibir las determinaciones internas entre fenómenos cambiantes, está también vigorosamente presente en el pensamiento (que intenta ser) crítico, cosa que se evidencia en múltiples disputas al interior de la misma escuela marxista. Tal es el caso, por ejemplo, del debate en torno al "mecanicismo" en
Marx, íntimamente ligado, como se apuntó, a la vasta y crónica incomprensión de su método dialéctico. De igual manera, el caso del histórico debate acerca de la "transformación de valores a precios de producción", que implica el cuestionamiento sobre la validez de la teoría laboral del valor para verdaderamente explicar y comprender el funcionamiento del modo de producción capitalista. He aquí, la importancia decisiva de esta discusión.

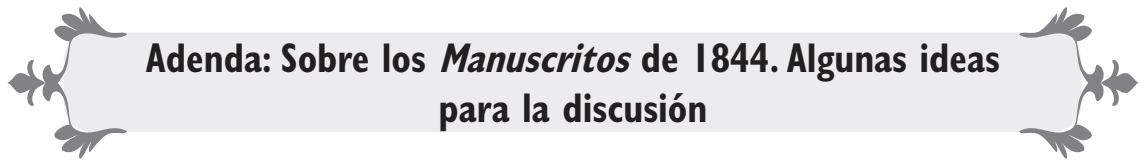

La ideología alemana, escrita por Marx y Engels entre 1845 y 1846, fuente principal de la concepción materialista de la historia, es obviamente posterior a las ideas contenidas en los Manuscritos, $^{8}$ y anterior a La miseria de la filosofía (de 1847), donde se empiezan a esbozar las nociones de lo que sería la teoría laboral del valor marxista. Lo extraordinariamente interesante de este período, de 1844 a 1847, es que Marx pasa del rechazo a la aceptación de, justamente, esa teoría laboral del valor que había sido elaborada con anterioridad por la economía política clásica: Adam Smith y David Ricardo (Mandel, 1971).

Este rechazo inicial, resultado sobre todo de la lectura de Ricardo y del descubrimiento de las demoledoras contradicciones contenidas en su teoría (e.g., el precio y el valor de las mercancías eran considerados como categorías idénticas, la incapacidad de explicar el origen de la ganancia a partir de la ley del valor, etc.), tenía como causa fundamental la necesidad de la economía política de considerar la realidad como algo puramente accidental, viéndose obligada a refugiarse en la abstracción formal para alcanzar la coherencia lógica. ${ }^{9}$ Así, la teoría dejaba de lado precisamente lo que se suponía que debía explicar: la realidad. De modo que las conclusiones a las que la teoría llegaba parecían contradecir lo que se observaba (la "competencia capitalista"). Por si fuera poco, tal teoría inadecuadamente abstracta, tendía a ocultar las relaciones de dominación y de alienación presentes en la sociedad como fruto "del movimiento de la propiedad privada" 
(Marx 2005 [1844], p. 117. Itálicas del autor). En definitiva, no era más que una construcción apologética del statu quo; obsérvese, además, que cuando Marx redacta los Manuscritos, la relación social de explotación capitalista aún no había sido detectada a cabalidad.

Sin embargo, ante las cínicas acusaciones de los detractores de Ricardo (Say, Sismondi, etc.), más cínicas aún que el cinismo con el que Marx calificara a Ricardo al inicio, y la urgencia de estos por abandonar la teoría laboral del valor ricardiana, más por socialmente peligrosa que por lógicamente inválida, Marx empieza a modificar su posición y a defender la teoría, hecho que se ve reflejado en los Manuscritos (ver, por ejemplo, Marx 2005 [1844], p. 123).

En efecto, la teoría laboral del valor parecía sugerir un cierto "derecho" del trabajador para reclamar todo el producto, en tanto, de acuerdo a esta teoría, era el trabajo la única fuente del valor y de la riqueza. La apropiación del producto excedente (plusvalía) por parte de la clase capitalista aparecía entonces como un fraude, un robo perpetrado contra la clase trabajadora, robo que después sería bautizado por Marx con el nombre de "explotación". La forma de distribución dominante, resultado del modo de producción dominante, quedaba así delatada y, por ende, sin justificación. Era por completo natural que el desarrollo de esta teoría, gracias a los trabajos de Ricardo, causara miedo e incomodidad, en tanto constituía una amenaza real a los intereses de la clase en el poder. Se trataba, por tanto, de defender el orden social frente a esta perniciosa doctrina, i.e. era necesario rechazarla, desacreditarla, desarticularla y anularla (cosa que prevalece hasta nuestros días). Esta fue la tarea de los que Marx denominara "economistas vulgares", sicofantes orgánicos a los ya mencionados intereses de la clase dominante. De ahí que Ricardo fuera tildado de ser el "padre del comunismo", y Marx de ser su discípulo. Y es que a los ojos de dichos economistas vulgares, los trabajos de Marx parecían ser la peligrosa continuación de los aportes de Ricardo transformados en una maquinaria de guerra (Dostaler, 1978). Por lo demás, las propiedades para la "agitación social" de esta teoría eran más que notables, algo valioso para los intereses de la clase explotada. Por supuesto, Marx y Engels no pasarían por alto esta observación. El tomo I de El capital, por ejemplo, había sido publicado en Paris tan solo cuatro años antes de que estallara la Comuna, lo que fue rápidamente interpretado como una muestra palpable de la dimensión de su peligro.

Es en La ideología alemana donde se patenta la aceptación definitiva que Marx (y Engels) hace(n) de esta teoría (Mandel, 1971). Pero 
esta aceptación de la teoría laboral del valor de la economía política clásica fue cualquier cosa menos ciega. Se trataba de estudiarla extensamente y a profundidad, de conocerla en detalle, de encontrar sus fallas, contradicciones y debilidades, de criticarla para superarla -en el sentido hegeliano-y completarla. Este proceso, que incluye el paso del proudhonismo al anti-proudhonismo de Marx, es un tema altamente complejo en el que, por el momento, no vamos a adentrarnos. Constituye, de hecho, toda la obra (aún inconclusa) de este autor. Baste decir que es aquí donde se desarrolla el método histórico-dialéctico y que surge una teoría general del valor-trabajo, también histórica.

Finalmente, algunas de las ideas cardinales que encontramos en los Manuscritos, y que luego evolucionaron en ese proceso de construcción del sistema teórico de Marx, son las siguientes:

El desarrollo de la categoría "alienación", como anterior a la de "explotación", y la idea de "esencia", o de "naturaleza humana", aún como categoría ahistórica y asocial. De acuerdo a Marx, tal esencia consistía en el poder creador humano, fin verdadero de la actividad productiva y que, en el capitalismo, era convertido en un simple medio para la satisfacción de las necesidades, i.e. para la subsistencia de las personas. Estas últimas se veían así reducidas a una mera existencia animal, y extrañadas tanto del producto de su trabajo como de los medios necesarios para llevarlo a cabo (propiedad privada). ${ }^{10}$

La noción de "libertad", presentada de forma similar, esto es, aún de manera ahistórica, y definida como negación (¿acaso con un toque de liberalismo?): la no necesidad, condición del ejercicio pleno del poder creador humano $y$, en definitiva, la negación de la propiedad privada como emancipación.

El carácter histórico del modo de producción capitalista, sus categorías y relaciones sociales propias, su movimiento y evolución, no estaban todavía en los Manuscritos enteramente identificados, ni ubicados rigurosamente en ese todo objeto de estudio, pero ya estaban, sin lugar a dudas, en camino de serlo. 


\section{Referencias bibliográficas}

os Dostaler, G. (1978), Valeur et Prix. Historie d'un débat, Montreal: Les Presses de l'Université du Québec

os Gill, L. (2002) Fundamentos y límites del capitalismo, Madrid: Editorial Trotta

os Macdonald, F. (1955) The Republic of Plato, London, Oxford, New York: Oxford University Press

os Mandel, Ernest (1971) The formation of the economic thought of Karl Marx, 1843 to Capital, New York: Monthly Review Press

os Marx, K. y Engels, F. (1973) La concepción materialista de la historia, Buenos Aires: Ediciones de la Larga Marcha

os Marx, K. (2005) [1844] Manuscritos de economía y filosofía, Madrid: Alianza Editorial

os Marx, K. (1973) [1857-58] Grundrisse: Foundations of the Critique of Political Economy, London: Penguin

os Russell, B. (1954) The Problems of Philosophy, Oxford: Oxford University Press

\section{Notas}

1 Vale mencionar que el entrenamiento de Platón no consiste en enseñar tales capacidades, sino en proporcionar los estímulos necesarios para que estas sean reveladas, liberadas del alma del filósofo. De ahí la importancia que para Platón tenía la selección meticulosa del(los) candidato(s). Esta es una postura claramente metafísica-idealista.

2 Como se sabe, esta fue una de las preocupaciones centrales en los trabajos de Marx y Engels, viz, el descubrimiento y estudio de las leyes que rigen la evolución histórica de las sociedades, y en particular, las que rigen el funcionamiento del modo de producción capitalista.

3 Estas fuerzas productivas no caen del cielo, ni avanzan como "caballo desbocado" por sí mismas, sino que son, también, producto de un proceso histórico, de un proceso de evolución humana —que no es, ni puede ser, completamente biológico- y de su relación con la naturaleza.

4 "A partir de cierto momento el desenvolvimiento de las fuerzas productivas se vuelve un obstáculo para el capital; por tanto la relación del capital se torna en una barrera para el desarrollo de las fuerzas productivas del trabajo. El capital, es decir, el trabajo asalariado, llegado a este punto entra en la misma relación con el desarrollo de la riqueza social y de las fuerzas productivas que el sistema cooperativo, la servidumbre de la gleba y la esclavitud, y, en su calidad de traba, se le elimina necesariamente. Con ello se quita la última figura servil asumida por la actividad humana, 
la del trabajo asalariado por un lado y el capital por el otro, y este despojamiento mismo es el resultado del modo de producción adecuado al capital; las condiciones materiales y espirituales para la negación del trabajo asalariado y del capital, las cuales son ya la negación de formas precedentes de la producción social que no es libre, son a su vez resultados del proceso de producción característico del capital. En agudas contradicciones, crisis, convulsiones, se expresa la creciente inadecuación del desarrollo productivo de la sociedad a sus relaciones de producción hasta hoy vigentes. La violenta aniquilación del capital, no por circunstancias ajenas al mismo, sino como condición de su autoconservación, es la forma más contundente en que se le da el consejo de que se vaya y deje lugar a un estadio superior de producción social" (Marx 1973 [1857-1858], p. 746. Traducido del inglés).

"El comunismo es la posición como negación de la negación, y por eso el momento real necesario, en la evolución histórica inmediata, de la emancipación y recuperación humana. El comunismo es la forma necesaria y el principio dinámico del próximo futuro, pero el comunismo en sí no es la finalidad del desarrollo humano, la forma de la sociedad humana" (Marx 2005 [1844], p. 152. Itálicas del autor). "Para nosotros, el comunismo no es un estado que debe implementarse, un ideal al que haya que sujetarse la realidad. Nosotros llamamos comunismo al movimiento real que anula y supera el estado de cosas actual" (Marx y Engels 1973, p. 37. Itálicas de los autores).

6 La combinación de estos elementos, i.e. el desarrollo elevado y universal de las fuerzas productivas, y la organización de un movimiento social también universal, posibilitaría, además, una acción "mundial" y "simultánea". De faltar una de estas dos condiciones, la transformación no ocurrirá aunque la idea de revolución sea proclamada cien veces ( $c f$. Marx y Engels 1973, p. 41).

7 Recuérdese que "[] as ideas de la clase dominante son las ideas dominantes en cada época" (Marx y Engels 1973, p. $50)$.

8 La crítica de la filosofía de Hegel la encontramos, sin embargo, ya bastante desarrollada en esta obra.

9 “[S]u abstracción”, refiriéndose a Ricardo, "llega a la cima de la infamia" (Marx, citado por Mandel 1971, p. 43. La traducción es nuestra).

10 Es interesante notar que esta forma de concebir la "esencia humana" es también propia de la economía neoclásica (la moderna "economía vulgar"). En ella, la racionalidad económica medio-fin, o racionalidad de maximización de la utilidad, se presenta como si se tratara de algo biológico o genético, de algo que forma parte de una supuesta naturaleza humana que siempre ha sido y será así. 